\title{
The implications of the use of cannabidiol-related products in a safety-sensitive drug testing environment: A medical-legal perspective
} \author{
M Jordaan, ${ }^{2}$ BSc Hons, MSc (Chem Path); A A S Marais, ${ }^{3}$ BSc, BSc Hons, MSc (Chem Path); \\ L G Curlewis, ${ }^{4}$ BLC, LLB, LLM (Proc Law), LLM (Lab Law), LLM (Comm Law), LLD \\ ${ }^{1}$ Department of Chemistry, Faculty of Agriculture and Natural Sciences, University of Pretoria, South Africa \\ ${ }^{2}$ Expert Laboratory Services, Pretoria, South Africa \\ ${ }^{3}$ Forensic Science Laboratory, South African Police Service, Pretoria, South Africa \\ ${ }^{4}$ Department of Procedural Law, Faculty of Law, University of Pretoria, South Africa
}

J Jooste, ${ }^{1}$ BSc, BSc Hons; J B Laurens, ${ }^{2}$ BSc (Ed), BSc Hons, MSc (Chem), MSc (Appl Tox), MPhil (Med Law), PhD (Chem), PhD (Med Law);

Corresponding author: JB Laurens (tim@expertlabservices.co.za)

Cannabis access laws allow for the use of cannabis in private and the trade, purchase and use of hemp-related products as a complementary medicine and for other benefits. Cannabidiol (CBD) has the treatment potential for several conditions but, with the lack of resources in South Africa to maintain the legislation, products contaminated with delta-9-tetrahydrocannabinol $\left(\Delta^{9}\right.$-THC) are sold by some suppliers who do not comply with the legislative provisions in terms of the threshold concentrations for $\Delta^{9}$-THC. This dilemma complicates a medical review officer's decision regarding intentional use of $\Delta^{9}$-THC or otherwise, since a CBD user may have purchased the product legally and in good faith. Hemp- and CBD-containing products were analysed by gas chromatography-mass spectrometry and compliance was assessed for $\mathrm{CBD}$ and $\Delta^{9}$-THC purity against the legislative thresholds. A strategy based on metabolite ratios is suggested to distinguish between intentional or irresponsible cannabis use and legitimate CBD use.

S Afr Med J 2021;111(10):942-945. https://doi.org/10.7196/SAMJ.2021.v111i10.15866

Cannabis sativa L. was brought to Africa by Arab traders, and has been cultivated for at least 5000 years for many established medical and historical purposes. ${ }^{[1-3]}$ Marijuana and hemp are colloquial names for cannabis strains of the same plant genus. Hemp is characterised by a low concentration of delta9-tetrahydrocannabinol $\left(\Delta^{9}\right.$-THC), the primary psychoactive compound in C. sativa, popularising hemp cannabidiol (CBD) oils, as the medical benefits can be obtained without the psychoactive effect of marijuana, the latter characterised by high concentrations of $\Delta^{9}$-THC.

CBD demonstrates a decreased agonism of the CB-1 receptor compared with $\Delta^{9}$-THC, explaining the absence of psychoactive effects. ${ }^{[4]}$ It is claimed that CBD can reduce the use of opioids owing to its antinociceptive effects in inflammation models, reducing heroin-seeking behaviour. ${ }^{[5-8]}$

After numerous calls for legalisation from the South African (SA) public and activists, despite some caution raised by academics, ${ }^{[9,10]}$ C. sativa access laws were passed, first by legalising the private use of cannabis, ${ }^{[11-14]}$ and secondly, by amendments to the schedules of the Medicines and Related Substances Act No. 101 of 1965 (Medicines Act), ${ }^{[15]}$ applying a threshold concentration approach for CBD and $\Delta^{9}$-THC.

As with all crucial decisions, unforeseen consequences have created dilemmas. One of these is that hemp products and CBD oils are contaminated with $\Delta^{9}$-THC owing to unregulated cannabis plant strains, ineffective enrichment and purification procedures, inadequate analytical quality control and testing and known law enforcement constraints to ensure product compliance in SA. These factors were legitimate concerns before legalisation, and have remained, since SA is a developing country that lacks resources to manage the broad social impact of legalisation. ${ }^{[16]}$

Medical practitioners who function as medical review officers (MROs) in the occupational health setting are confronted with the difficulty of distinguishing between intentional or negligent use of $\Delta^{9}$-THC where it is prohibited, as opposed to non-intentional administration using complementary medicine. Delta-9-THC contamination of CBD oils is also critical in other areas where medical practitioners advise on test results: for school drug-testing programmes where $\mathrm{CBD}$ oils are sometimes administered to learners by their parents as complementary medicine; parents in custody cases being tested for substance abuse and adjudicated in SA family courts; sports doping tests where such substances are prohibited; and driving under the influence of intoxicating substances.

The risks of incorrect interpretation regarding cannabis testing results have two aspects. First, there is the possibility of crossreactivity of the screening due to non-specific interference from other cannabinoids, leading to false positives, most common in immunoassays. ${ }^{[17]}$ Second, there are difficulties in discriminating the source of $\Delta^{9}$-THC in the case of true positives.

The legitimate use of CBD-enriched oil as complementary medicine has gained a tremendous amount of traction recently. Its use as complementary medicine, or as edible and drinkable products, is legal if compliant with the schedules of the Medicines Act. ${ }^{[15,18]}$ There is a danger of compromising safety in the workplace and triggering positive drug tests if the products are contaminated with $\Delta^{9}$-THC. ${ }^{[19-22]}$

The use of CBD-related products may also become the first line of defence for individuals who smoke cannabis and fail threshold drug 
tests in the workplace. An uninformed MRO decision may also result in injustice if an individual uses a hemp product not knowing that it is contaminated with $\Delta^{9}$-THC.

\section{Relevant legislation}

The fundamental human rights related to the legal use of cannabis and its refined products must be balanced against the health and safety of others. ${ }^{[23]}$ The relevant human rights of privacy, freedom, autonomy, freedom of religion and the equal enjoyment of rights and privileges are indicated in the Bill of Rights of the Constitution of the Republic of SA. ${ }^{[24]}$ The legalisation in effect confirmed that cannabis and hemp product users should enjoy equal protection and benefit of the law, including the enjoyment of rights and freedom. ${ }^{[25]}$

The legalisation of the private use of cannabis also did not preclude the health and safety legislation and regulations applicable to workplaces and risk-sensitive environments. ${ }^{[2,27]}$ Screening and confirmation threshold testing, followed by validation by a MRO, are mainly utilised to detect individuals with prohibited substances in their bodies. ${ }^{[28]}$

The schedules of the Medicines Act classify CBD-containing products for human consumption as follows: ${ }^{[15]}$

- All products intended for human ingestion with a $\Delta^{9}$-THC purity greater than 0.001 mass percentage are classified as schedule 6 .

- All CBD-containing products are classified in schedule 4, unless the products are indicated as complementary medicine, with a total mass of less than $600 \mathrm{mg}$ CBD per package, intended to be administered in a regimen of less than $20 \mathrm{mg}$ CBD per dose. A product that complies with this specification is classified in schedule 0 .

Any person may possess substances in schedules 0 - 2 for medicinal purposes. Schedule 3 - 6 substances require a prescription issued by an authorised prescriber for a product registered for use in SA by the South African Health Product Regulatory Authority (SAHPRA). ${ }^{[29]}$ Manufacturers and suppliers must comply with the legal thresholds for $\Delta^{9}$-THC and CBD in their products to trade in these formulations legally and avoid liability and possible prosecution.

\section{Composition of cannabis plant extract}

Cannabis originates from the plant C. sativa, of which C. indica and C. ruderalis are subspecies. ${ }^{[2,30-32]}$ Cannabis contains cannabinoids, ${ }^{[33]}$ such as cannabidiol (CBD), $\Delta^{9}$-tetrahydrocannabinol $\left(\Delta^{9}\right.$-THC), cannabinol (CBN) and tetrahydrocannabivarin (THCV), of which the last three are psychoactive. ${ }^{[2]}$ Most of the psychotropic effects are caused by $\Delta^{9}$-THC. ${ }^{[2,322,34,35]}$ In contrast, CBD is considered nonpsychoactive, although it shows positive psychological effects in terms of anxiety and depression ${ }^{[2]}$ and can modulate the psychoactive effects of $\Delta^{9}$-THC. ${ }^{[36]}$

C. indica variants or hemp plants ${ }^{[35,37]}$ are known to have higher CBD but lower $\Delta^{9}$-THC contents. ${ }^{[32,35]}$ In contrast, sativa variants or marijuana have lower $\mathrm{CBD}$ and higher $\Delta^{9}$-THC contents, up to $25 \%(\mathrm{w} / \mathrm{w}){ }^{[32]}$ Hemp is preferred for the manufacture of CBD oils, ${ }^{[38]}$ but all cannabis plants contain $\Delta^{9}$-THC to some extent, ${ }^{[39]}$ and the extraction processes used to isolate $\mathrm{CBD}$ from plant materials also extract other biologically active compounds such as CBN and $\Delta^{9}$ THC. ${ }^{[40]}$

The need for CBD purification is illustrated by studies wherein commercially available CBD products were analysed. These studies found that upwards of $50 \%$ of the researched products contained CBD levels that did not correspond with the product labelling. Additionally, $85 \%,{ }^{[31]} 20 \%{ }^{[41]}$ and $100 \%{ }^{[42]}$ of the products analysed by each study, respectively, had detectable levels of $\Delta^{9}$-THC, with concentrations ranging up to and exceeding the minimum dose of $\Delta^{9}$-THC, $2.5 \mathrm{mg} /$ day, above which adverse effects arise.

The present study reports $\mathrm{CBD}, \Delta^{9}$-THC and CBN levels in a sample of commercially available hemp-related products in SA, analysed in a forensic laboratory with a validated gas chromatography-mass spectrometry (GC-MS) analytical method. The products are assessed for compliance with current legislative threshold specifications for $\mathrm{CBD}$ and $\Delta^{9}$-THC, to provide information to medical practitioners responsible for determining the risk of an individual's possible cannabis consumption to an organisation.

\section{Discussion \\ Experimentally obtained $\Delta^{9}$-THC, CBD and CBN concentrations}

Products from the local SA market were purchased and analysed for CBD, CBN and $\Delta^{9}$-THC by GC-MS isotope dilution, with a linear non-weighted response model. Eight CBD-based products comprising four oils for oral consumption, one 'vape' oil, one tincture, one tea and one chewing gum, obtained from either online shops, cannabis shops, pharmacies or cannabis industry expos, were analysed.

The following non-compliances were observed:

- One of the oils with a dark appearance exceeded the legal limit for the $\Delta^{9}$-THC content, at $3.809 \%$, or $54.82 \mathrm{mg}$, which is 22 times higher than the psychoactive dose. ${ }^{[42]}$ This places the product under schedule 6 . In addition, the total CBD content for the product was $31.38 \mathrm{mg}$.

- False advertising was a prominent feature, with two of the oils reported as having 'no THC', but containing 3.8 and $3.2 \mu \mathrm{g}$, respectively.

- The CBD contents of the chewing gum and the vape oil were significantly lower than the reported values.

- CBN was detected in all the samples, with masses ranging up to $0.6 \mathrm{mg}$. CBN can trigger a positive screening test. ${ }^{[43]}$

- Products purported to contain a total mass of $1000 \mathrm{mg}$ CBD instead of the legal limit of $600 \mathrm{mg}$ CBD were also available in one of the cannabis shops.

\section{Pharmacodynamics and pharmacokinetics of CBD and $\Delta^{9}$-THC}

$\mathrm{CBD}$ and $\Delta^{9}$-THC have similar pharmacokinetics. The shared highly lipophilic character of $\Delta^{9}$-THC and CBD results in rapid distribution throughout the body, with both compounds metabolised in the liver by cytochrome P450 enzymes. ${ }^{[4]}$

These compounds are mainly excreted in the faeces as un-metabolised compounds, ${ }^{[4,45]}$ and in the urine as metabolites THC- $\mathrm{COOH}^{[46]}$ and $\mathrm{CBD}$-glucuronide. ${ }^{[45]}$ The elimination half-life of these compounds is similar, ranging from 3 to 4 days for THC$\mathrm{COOH}^{[46]}$ and 2 to 5 days for $\mathrm{CBD}{ }^{[46]}$ Therefore, a similar detection window is expected.

\section{Synthesis: Legislation, science and ethics}

The cannabis access laws in the form of amendments to the Drugs and Drug Trafficking Act No. 140 of 1992, ${ }^{[47]}$ the Medicines Act ${ }^{[48]}$ and their respective schedules should, in principle, not affect drug test results performed as part of a health and safety programme in workplaces and other areas where drug tests are performed. The national health and safety legislation did not change, and it is still the responsibility of employers to ensure a safe workplace, which includes drug testing. However, $\Delta^{9}$-THC-contaminated hemp and CBD products can affect cannabis drug test results in unforeseen ways. 
First, CBD product (primarily oils and tinctures) use may trigger positive drug tests since $\Delta^{9}$-THC can accumulate in the human body owing to its lipophilic character and extensive half-life, exceeding administrative thresholds or cut-off concentration values. Second, it may become a first-line defence for non-negative screening tests and positively confirmed $\Delta^{9}$-THC test results. The integrity of such a defence must be interrogated if a transgression by the employee of workplace policy or contract has indeed occurred, where a delictual liability exists or where criminal sanctions may apply.

The absence of intent must be kept in mind when the MRO assesses the organisation's risk due to the possible use of cannabis by the individual. A strict liability approach is not justified in a workplace drug testing programme, but decisive action must follow for users with no legitimate excuse for intentional or negligent use.

It will be a complex task for the MRO to investigate whether $\Delta^{9}$-THC ingestion is due to the ingestion of a contaminated CBD oil product. The MRO may consider analysing the product to verify the $\Delta^{9}$-THC purity, since a non-compliant CBD product is already suspicious. Doubt will, however, not be eliminated even if the product does comply with the legislative requirements. Dosage frequency, dose amounts, and the continuous homoeostatic process related to the body's hydration status, which may concentrate drug metabolites in the urine, are all bioaccumulation factors that must be considered.

It will also be problematic for a company to prohibit and enlist the use of hemp- and CBD-containing complementary medicine, purchased legally, in good faith and used correctly according to the prescribed dose regimen in schedule 0 . For this reason, legitimate use of CBD products should be considered carefully to exclude the possibility of a confirmed positive test result due to the use of such products that may be contaminated with $\Delta^{9}$-THC.

The prohibition of cannabis use and possession in a workplace could justify invoking the Constitutional limitation-of-rights clause within reasonable boundaries. ${ }^{[27]}$ However, in the authors' opinion, it is doubtful that this can be justified for a schedule 0 substance such as $\mathrm{CBD}$ when used within all legal bounds.

The issue of contaminated hemp and CBD products may be attributed to the fact that SA does not have adequate resources to maintain the Medicines Act and related regulations' legislative provisions. Also, advertising the products by stating that the product 'contains no THC' is a qualitative statement that should be supported with a definitive value. If the purities are not reported accurately, it amounts to false advertising, which has far-reaching consequences. The authors believe that all cannabis test results must be cautiously treated on a case-by-case basis (ad hoc), even after future mandatory SAHPRA product registration has occurred.

It is relatively easy to imagine the large number of legitimate and illegitimate defences that will be used once roadside testing for cannabis starts in SA.

\section{The way forward}

The authors suggest that an experimentally obtained normal reference range of CBD: $\Delta^{9}$-THC ratio of drug metabolites in urine or oral fluid be considered, which should be available from a reputable drug testing confirmation laboratory. The CBD: $\Delta^{9}$-THC-COOH ratio in urine and possibly also a CBD: $\Delta^{9}$-THC ratio for oral fluid can be employed to identify a THC user. A CBD user will have a larger ratio compared with that of a THC user. It will not take long for some cannabis users to understand that a 'normal' CBD: $\Delta^{9}-\mathrm{THC}$ ratio can be skewed by CBD co-administration. Therefore, more research is required to discover unique and selective markers that will enable more accurate discrimination between $\Delta^{9}$-THC and CBD users.

\section{Conclusions}

The recent changes in the schedules of the Medicines Act related to $\mathrm{CBD}$ necessitate proper quality control of CBD products from a compliance drug-testing perspective. The analysis of commercial products containing CBD highlighted quality-control shortcomings. Products commonly did not match the CBD values listed on their packaging, and one of the products was contaminated with $\Delta^{9}$-THC, showing levels far above the SA legislative threshold of 0.001 mass percent. CBD users risk administering unknown amounts of cannabinoids, including $\Delta^{9}$-THC, and are at risk of positive cannabis drug test results.

It is recommended that medical practitioners consider CBD: $\Delta^{9}$-THC metabolite ratios in urine or oral fluid to distinguish between an intentional or irresponsible cannabis user and a legitimate CBD user.

\section{Declaration. None}

Acknowledgements. None.

Author contributions. The authors contributed equally to the initial concept and preparation of the manuscript.

Funding. None.

Conflicts of interest. None.

1. Anizan S, Milman G, Desrosiers N, Barnes AJ, Gorelick DA, Huestis MA. Oral fluid cannabinoi concentrations following controlled smoked cannabis in chronic frequent and occasional smokers. Analytical Bioanalytical Chem 2013;405(26):8451-8461. https://doi.org/10.1007/s00216-013-7291-5

Analytical Bioanalytical Chem 2013;405(26):8451-8461. https://doi.org/10.1007/s00216-013-7291-5
Steenson S, Chambers L. Cannabidiol: A budding industry! Nutr Bull 2019;44(3):228-240. https://doi. org/10.111/nbu. 12395

3. Willis S. Drugs of Abuse. London: Pharmaceutical Press, 2005.

4. Fasinu PS, Phillips S, ElSohly MA, Walker LA. Current status and prospects for cannabidiol preparations as new therapeutic agents. Pharmacotherapy 2016;36(7):781-796. https://doi.org/10.1002/phar.1780

5. Donvito G, Nass SR, Wilkerson JL, et al. The endogenous cannabinoid system: A budding source of targets for treating inflammatory and neuropathic pain. Neuropsychopharmacology 2018;43(1):52-79. https://doi.org/10.1038/npp.2017.204

6. Ren Y, Whittard J, Higuera-Matas A, Morris CV, Hurd YL. Cannabidiol, a nonpsychotropic component of cannabis, inhibits cue-induced heroin seeking and normalizes discrete mesolimbic neuronal disturbances. J Neurosci 2009;29(47):14764-14769. https://doi.org/10.1523/neurosci.4291-09.2009

7. Hurd YL, Yoon M, Manini AF, et al. Early phase in the development of cannabidiol as a treatment for addiction: Opioid relapse takes initial center stage. Neurotherapeutics 2015;12(4):807-815. https://doi org/10.1007/s13311-015-0373-7

8. Hurd YL. Cannabidiol: Swinging the marijuana pendulum from 'weed' to medication to treat the opioid epidemic. Trends Neurosci 2017;40(3):124-127. https://doi.org/10.1016/j.tins.2016.12.006

9. Parry CDH, Myers BJ. Legalising medical use of cannabis in South Africa: Is the empirical evidence sufficient to support policy shifts in this direction? S Afr Med J 2014;104(6):399-400. http://dx.doi. org/10.7196/SAMJ.8135

10. Parry C, Myers B. Beyond the rhetoric: Towards a more effective and humane drug policy framework in South Africa. S Afr Med J 2011;101(10):704-706.

11. Prince v Minister of Justice and Constitutional Development 2013 No. 8760 (WCC).

12. Rubin v National Director of Public Prosecution 2013 No. 7295 (WCC).

13. Acton v National Director of Public Prosecution 2012: 31 March 2017, No. 4153 (WCC)

14. Minister of Justice and Constitutional Development v Prince 2018 CCT 108/17 (ZACC)

15. Amendment to the Schedules of the Medicines and Related Substances Act 101 of 1965 . Government Amendment to the Schedules
Gazette No 43347, May 2020.

16. De V van Niekerk JP. Medical marijuana and beyond. S Afr Med J 2014;104(6):387. http://doi org/10.7196/SAMJ.8335

17. Kroner GM, Johnson-Davis KL, Doyle K, McMillin GA. Cannabinol (CBN) cross-reacts with two urine immunoassays designed to detect tetrahydrocannabinol (THC) metabolite. J Appl Lab Med 2020;5(3):569-574. https://doi.org/10.1093/jalm/jfaa020

18. Burnett M, Fasken P, Gilbert R. Changes to the scheduling of cannabis, THC and CBD explained. Medical Brief 2020. https://www.medicalbrief.co.za/archives/fasken-changes-to-the-scheduling-of-cannabis-thcand-cbd-explained/ (accessed 9 April 2021).

19. US Food and Drug Administration. Warning letters and test results for cannabidiol-related products, 2015-2017. https:// www.fda.gov/NewsEvents/PublicHealthFocus/ucm 484109.htm (accessed 9 April 2021).

20. Fortner N, Fogerson R, Lindman D, et al. Marijuana-positive urine test results from consumption of hemp seeds in food products. J Anal Toxicol 1997:21:476-481. https://doi.org/10.1093/jat/21.6.476

21. Callaway JC, Weeks RA, Raymon LP, et al. A positive THC urinalysis from hemp (cannabis) seed oil. J Anal Toxicol 1997:21:319-320. https://doi.org/10.1093/jat/21.4.319

22. Struempler RE, Nelson G, Urry EM. A positive cannabinoids workplace drug test following the ingestion of commercially available hemp seed oil. J Anal Toxicol 1997:21:283-285. https://doi.org/10.1093/ jat $/ 21.4 .283$

23. Constitution of the Republic of South Africa, Chapter 2, section 36.

24. Constitution of the Republic of South Africa, Chapter 2, section 9, 12, 14, 15 .

25. Constitution of the Republic of South Africa, Chapter 2, section 9(1) and 9(2).

26. South Africa. Occupational Health and Safety Act No. 85 of 1993. Sections 8, 9, 14, 23; Section 2(A), 2 (C) of the regulations in terms of the Occupational Health and Safety Act.

27. South Africa. General Administrative Regulations of the Machinery and Occupational Safety Act No. 6 of 1983. Regulations 6 and 12(2).

28. Laurens JB, Carstens PA. Cannabis legalisation and testing for cannabis use in safety- and risk-sensitive environments. S Afr Med J 2020:110(10):995-998. https://doi.org/10.7196/SAMJ.2020.v1 10i10.14615 29. South Africa. Schedules of the Medicines and Related Substances Act No. 101 of 1965 
30. Merlin MD. Archaeological evidence for the tradition of psychoactive plant use in the old world. Econ Bot 2003;57(3):295-323. https://doi.org/10.1663/0013-0001(2003)057[0295:AEFTTO]2.0.CO;2

31. Ashton CH. Adverse effects of cannabis and cannabinoids. Br J Anaesth 1999;83:637-649. https://doi Ashton CH. Adverse effect
org $/ 10.1093 /$ bja/ 83.4 .637

32. Pate DW. Taxonomy of cannabinoids. In: F Grotenhermen, E Russo, editors. Cannabis and Cannabinoids: Pharmacology, Toxicology, and Therapeutic Potential. Philadelphia: Haworth Press, 2002:15-22.

33. Hazekamp A, Fischedick JT. Cannabis - from cultivar to chemovar. Drug Test Anal 2012;4:660-667 https://doi.org/10.1002/dta.407

34. Maurer HH, Sauer C, Theobald, DS. Toxicokinetics of drugs of abuse: Current knowledge of the isoenzymes involved in the human metabolism of tetrahydrocannabinol, cocaine, heroin morphine, and codeine. Ther Drug Monit 2006;28(3):447-453. https://doi.org/10.1097/01. ftd.0000211812.27558.6e

35. ElSohly, MA. Chemical constituents of cannabis. In: F Grotenhermen, E Russo, editors. Cannabis and Cannabinoids: Pharmacology, Toxicology, and Therapeutic Potential, Philadelphia: Haworth Press, 2002:27-36.

36. Thomas BF, ElSohly MA. The Analytical Chemistry of Cannabis: Quality Assessment, Assurance, and Regulation of Medicinal Marijuana and Cannabinoid Preparations. Amsterdam: Elsevier, 2016. https:// Regulation of Medicinal Marijuana
doi.org/10.1016/C2014-0-03861-0

37. Pavlovic R, Nenna G, Calvi L, et al. Quality traits of 'cannabidiol oils': Cannabinoids content, terpene fingerprint and oxidation stability of European commercially available preparations. Molecules 2018;23(5):1230. https://doi.org/10.3390/molecules23051230

38. Citti C, Russo F, Linciano P, et al. Origin of $\Delta 9$-tetrahydrocannabinol impurity in synthetic cannabidiol. Cannabis Cannabinoid Res 2021;6(1):28-39. https://doi.org/10.1089/can.2020.0021

39. Pertwee RG. Cannabinoid pharmacology: The first 66 years. Br J Pharmacol 2006;147:S163-S171. https://doi.org/10.1038/sj.bjp.0706406
40. Attard TM, Bainier C, Reinaud M, et al. Utilisation of supercritical fluids for the effective extraction of waxes and cannabidiol (CBD) from hemp wastes. Ind Crops Prod 2018;112:3846. https://doi. org/10.1016/.jindcrop.2017.10.045

41. Bonn-Miller MO, Loflin MJE Thomas BE. Labeling accuracy of cannabidiol extracts sold online. JAMA 2017;318(17):1708-1709. https://doi.org/10.1001/jama.2017.11909

42. Lachenmeier DW, Habel S, Fischer B, et al. Are side effects of cannabidiol (CBD) products caused by tetrahydrocannabinol (THC) contamination? F1000Research 2020;8:1394. https://doi.org/10.12688/ 1000research.19931.

43. Kroner GM, Johnson-Davis KL, Doyle K, McMillin GA. Cannabinol (CBN) cross-reacts with two urine immunoassays designed to detect tetrahydrocannabinol (THC) metabolite. J Appl Lab Med 2020;5(3):569-574. https://doi.org/10.1093/jalm/ffaa020

44. Chayasirisobhon S. Mechanisms of action and pharmacokinetics of cannabis. Perm J 2020;25:1-3. https://doi.org/10.7812/tpp/19.200

45. Ujváry I, Hanuš L. Human metabolites of cannabidiol: A review on their formation, biological activity, nd relevance in therapy. Cannabis Cannabinoid Res 2016:1(1):90-101. https://doiorg/10.1089/ can.2015.0012

46. Goldberger B, Miller JR. Handbook of Workplace Drug Testing. 2nd ed. London: AACC Press, 2009.

47. South Africa. Drugs and Drug Trafficking Act No. 140 of 1992.

48. South Africa. Medicines and Related Substances Control Act No. 101 of 1965.

Accepted 15 June 2021. 